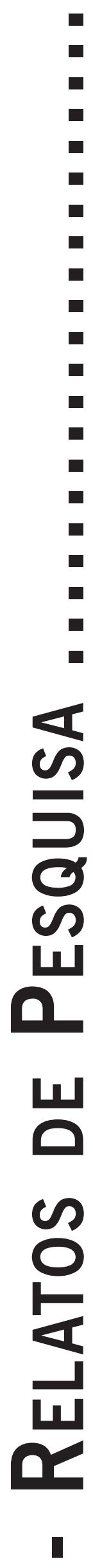




\title{
CONVIVÊNCIA COM ANIMAIS DE ESTIMAÇÃO: UM ESTUDO FENOMENOLÓGICO
}

\author{
Living with pets: a phenomenological study
}

La vida con los animales domésticos: un estudio fenomenológico

\author{
RAÍsA DuQuia GIUMELLI \\ Marciane Cleuri Pereira Santos
}

\begin{abstract}
Resumo: O presente artigo apresenta uma pesquisa sobre a influência da convivência com animais de estimação na vida das pessoas a partir da percepção dos tutores. Os voluntários para a realização da pesquisa foram seis estudantes universitários, tutores de no mínimo um animal de estimação. Através da aplicação de entrevistas semiestruturadas, foi possível coletar o perfil dos participantes, as percepções que eles possuem sobre a influência dos animais de estimação na vida das pessoas, os benefícios, os aspectos negativos e os sentimentos envolvidos nessa relação. A média de idade dos participantes da pesquisa foi de 22 anos, sendo dois participantes do sexo masculino e quatro do sexo feminino. Analisando os resultados obtidos através do método fenomenológico observou-se que todos os entrevistados trouxeram elementos positivos na relação com seus animais, enquanto os aspectos negativos foram associados com cuidados de higiene, doenças e morte do animal.
\end{abstract}

Palavras-chave: Animais de estimação; Relação homem-animal; Pesquisa Fenomenológica.

Abstract: This article presents a research about the influence of living with pets in people's life, from the perception of pet tutors. The volunteers for the research were six students of university, tutors of at least one pet. Through semi-structured interviews, it was possible to collect the participant's profile, their perception about the influence of pets in people's life, the benefits, the harm and feelings involved in this relationship. The participants' average age was 22 years old, two being male and four being female. Analysing on the results obtained through the phenomenological method, it was observed that all the interviewees brought positive elements in the relationship with their pets, while the negatives were associated with hygiene, disease and death of the animal. Keywords: Pets; Human-animal's relationship; Phenomenological research.

Resumen: Este artículo presenta una investigación sobre la influencia de vivir con animales domésticos en la vida de las personas, desde la percepción de los tutores. Los voluntarios para la investigación fueron seis estudiantes universitarios, tutores de al menos una mascota. A través de entrevistas semi-estructuradas, fue posible reunir el perfil del participante y su percepción acerca de la influencia de las mascotas en la vida de las personas, asi como de los beneficios, daños y sentimientos involucrados en esta relación. La edad promedio de los participantes fue de 22 años, dos hombres y cuatro mujeres. Analizando los resultados obtenidos a través del método fenomenológico, se observó que todos los entrevistados presentaron puntos positivos sobre la relación con sus mascotas, mientras que los negativos se asociaron con la higiene, la enfermedad y la muerte del animal.

Palabras clave: Animales; Relación del humano-animal; Investigación fenomenológica.

\section{Introdução}

A relação dos animais com o homem tem início já na pré-história, quando os animais eram utilizados como forma de proteger o território em que o homem vivia, dando auxílio a caças e transporte de cargas e humanos (Caetano, 2010). O homem sempre dependeu de interações com outras espécies para a sua sobrevivência, sendo que esta relação a priori era de predação, passando mais tarde para a domesticação (Hart, 1985). Conforme essa interação foi se desenvolvendo, surgiram ideias a respeito da utilização de animais como recurso terapêutico. No Brasil, em meados da década de 1950, a Doutora Nise da Silveira utilizou animais para tratamento de pessoas em um hospital psiquiátrico no Rio de Janeiro. Por volta de 1960, o Dr. Boris Levinson utilizou animais para trata- mento com crianças (Vivaldini, 2011). Nos últimos anos vários profissionais das áreas da saúde estão utilizando animais como recurso de tratamentos físicos e psíquicos (Lima \& Souza, 2004). Segundo Costa (2006), os animais de estimação proporcionam melhoria da qualidade de vida para as pessoas, no sentido que eles trazem estados de felicidade, diminuem sentimentos de solidão e auxiliam na melhora de condições físicas e psíquicas. No Brasil utiliza-se a equoterapia, que é o uso de cavalos como recurso terapêutico (Copetti, Mota, Graup, Menezes \& Venturi, 2007), a Terapia Assistida por Animais e a Atividade Assistida por Animais (Dotti, 2005).

Atualmente, segundo a Associação Brasileira da Indústria de Produtos para Animais de Estimação, o Brasil é o quarto país com a maior população de animais do mundo - cerca de 106 milhões, ficando atrás da China, 
Estados Unidos e Reino Unido (Abinpet, 2014), e é o segundo maior país no mercado de pets ${ }^{1}$, perdendo somente para Estados Unidos (Walsh, 2009). Dentre os vários motivos para as pessoas obterem um animal de estimação, alguns são que esses animais são dotados de muita energia, interagem com o ser humano espontaneamente e possuem um amor incondicional por seus tutores (Nebbe, 2000). Na literatura internacional foram criadas escalas cujo objetivo é medir o vínculo estabelecido entre o homem e o animal, sendo alguns desses testes o Companion Animal Bonding Scale, Pet Attitude Scale-Modified and Pet Relationship Scale (Anderson, 2006).

Considerando a relevância que os animais possuem na vida das pessoas buscou-se com esta pesquisa identificar a influência do convívio com animais de estimação na vida das pessoas a partir da percepção dos tutores. Para isso, foram realizadas entrevistas com seis estudantes universitários da Universidade da Região de Joinville (Univille), que possuem algum animal de estimação, e então foram transcritas as percepções delas sobre a influência de conviver com um animal de estimação, os benefícios, aspectos negativos e sentimentos envolvidos nessa relação. Para a elaboração deste artigo foi utilizado o termo "tutor", que segundo o Dicionário de Língua Portuguesa Aurélio, é aquela pessoa no qual é o protetor e é confiada a tutela de cuidar. Termos como "dono" ou "proprietário" remetem a impressão de posse, olhando o animal como o objeto, e o intuito do artigo é discutir sobre uma relação entre seres vivos. Portanto, não foram usados esses termos.

\section{História da Relação do Homem com o Animal}

A interação dos animais com o ser humano aparece fortemente desde os tempos primitivos (Caetano, 2010). Estudos mostram que a interação homem-animal pode ter surgido a partir de um lobo que desenvolveu características mais dóceis ao se relacionar com o homem, e este o utilizou para auxílio na caça e para proteger sua moradia. Outra hipótese para o surgimento da relação homem-animal pode ter ocorrido na época de grandes temperaturas baixas e fome, durante a qual o homem utilizava o cão para se aquecer e retribuía o animal com restos de comida (Fuchs, 1987). Segundo Perls, Hefferline e Goodman (1997), o ser humano se ajusta de forma criativa no meio com o objetivo de satisfazer as principais necessidades do momento, a partir do que esse ambiente tem como possibilidades. Essa satisfação de necessidades traz ao ser humano um equilíbrio e é uma forma de ele se autorregular. Nesse sentido o animal, portanto, foi uma alternativa encontrada pelo homem para satisfazer sua necessidade de proteção e aquecimento. Barros (2008) traz também que já foram encontrados, em sítios arqueológicos, vários

\footnotetext{
O termo"pet" vem do francês "petit" e significa algo que dá prazer e companhia (Walsh, 2009).
}

ossos de seres humanos enterrados junto com ossos de animais. Na idade moderna, os animais eram utilizados também como cães de guarda, como meio para levar carroças e trenós e acompanhar tropeiros e agricultores (Berzins, 2000). Na idade do bronze e do ferro, os cavalos eram muito utilizados como meio de transporte, por serem considerados mais rápidos que outros meios (Levine, 1999). Essa interação com os animais apareceu também na mitologia, com deuses que tinham a composição de animais misturados com humanos, representando valores, proteção e esperança (Dotti, 2005). Atualmente, é possível verificar que os animais estão presentes e possuem papel muitas vezes ativo em desenhos animados, filmes, livros e propagandas (Garcia, 2009).

\section{Animais na legislação}

Os animais possuem também lugar nas Leis Federais, como o Decreto 24.645, de 10 de junho de 1934 (Brasil, 1934), que estabelece medidas de proteção aos animais e a Lei $\mathrm{n}^{0} 9605$ de 12 de fevereiro de 1998 (Brasil, 1998), que trata sobre os crimes ambientais, entre eles os maus tratos aos animais. A nível municipal, em Joinville, Santa Catarina, no mês de maio de 2013 foi elaborado o decreto $\mathrm{n}^{0} 20.644$ que regulamenta as disposições da lei complementar no360 de dezembro de 2011, no qual discorre sobre a Proteção do Animal do Município de Joinville. Na cidade, todos os cães devem ser identificados através da implantação de microchips no corpo deles, por meio de um médico veterinário, contendo informações sobre o animal e seus tutores (Jornal do Município de Joinville, 2013).

Segundo o site da prefeitura de Araquari, Santa Catarina, em maio de 2014, o prefeito da cidade sancionou uma nova lei, de número 2917/2014 voltada à proteção dos animais, controle reprodutivo destes e conscientização das pessoas sobre abandono, maus tratos e incentivo à adoção. A prefeitura ainda estabeleceu uma parceria com a ONG Projeto Esperança Animal (PEAA) para elaboração de palestras nas escolas no qual um dos temas é a proteção dos animais. Além disso, a Fundação Municipal do Meio Ambiente (FUNDEMA) ajuda com a esterilização de animais de rua que posteriormente são submetidos à adoção. As pessoas da cidade de Araquari que adotam esses animais podem ter desconto do IPTU e são fiscalizados pela prefeitura para garantir todos os cuidados que o animal adotado precisa (Prefeitura de Araquari,2014).

\section{A relação do homem com o animal}

Segundo Tatibana e Costa-Val (2009), crianças que convivem com animais de estimação se tornam mais afetivas, solidárias, sensíveis, com maior senso de responsabilidade, e compreendem melhor o ciclo vida-morte. Algumas pessoas idosas tratam os animais de estimação como 
membros da própria família. Ter um animal de estimação nessa fase da vida pode promover alívio e conforto em momentos de perdas e mudanças, que são comuns nessa etapa, além de possibilitar uma melhor auto-estima, e estimular a convivência social (Costa, 2006). A presença do animal de estimação no lar pode estimular também pessoas sedentárias e obesas a realizarem exercícios físicos (Tatibana \& Costa-val, 2009). Nas famílias americanas, a maioria dos tutores consideram seu animal de estimação como um amigo e/ou membro da família (Walsh, 2009).

Os animais de estimação, além de uma companhia, são também utilizados para caça, proteção e auxílio de pessoas com dificuldades de locomoção (Garcia, 2009). Nesse sentido, pode-se dizer que essa é uma relação EU e ISSO, que Buber (1974) define como uma relação em que o "isso" é considerado um objeto para ser utilizado com uma finalidade.

Em determinados momentos esta relação torna-se EU-TU. Esse tipo de relação caracteriza-se por uma interação genuína com o outro, no qual reconhecemos e aceitamos a sua condição de ser existencial. O termo "tu" pode ser tanto uma pessoa, um elemento da natureza, uma divindade ou um animal. Tanto a relação "EU-TU”, como a relação "EU- ISSO” são essenciais para o desenvolvimento humano (Buber, 1974).

É importante considerar, além da perspectiva do homem, os benefícios e malefícios na perspectiva do animal de estimação nesta relação homem animal. Segundo Franco (2001) a interação do homem com o animal de estimação, mesmo se mostrando afetuosa, se caracteriza por uma relação de autoritarismo, visto que é o homem que decide sobre a liberdade do animal, quando quer dar carinho para ele, e se vai impedir a reprodução dele ou não, por meio da castração. Quando o animal é utilizado como instrumento em terapias, Dotti (2005) coloca que é importante verificar o quanto o trabalho realizado será benéfico para o animal também, não tornando uma atividade que cause estresse para ele, entre outras consequências.

Outro aspecto no qual mostra o quanto esse fenômeno da relação do ser humano com os animais de estimação está presente é a grande variedade de produtos e alimentos voltados aos animais, trazendo a possibilidade do tutor comprar cada vez mais itens e colocar o seu animal como consumidor também (Bernard e Demaret, 1996 citado por Delarissa, 2003).

\section{Terapia Assistida por Animais}

Nos anos noventa, surge o termo Terapia Assistida por Animais (TAA), utilizado até hoje. A TAA é realizada por profissionais capacitados da área da saúde, que utilizam o animal como ferramenta terapêutica, com o objetivo de desenvolver e melhorar as condições físicas, sociais, emocionais e cognitivas de pessoas. Existe também a Atividade Assistida por Animais (AAA) que são visitas do animal que ocorrem de forma esporádica e possuem o objetivo de entretenimento e recreação (Dotti, 2005). A TAA pode ser aplicada a pessoas de todas as idades e o animal mais utilizado é o cão, porém outros animais como gatos, coelhos, chinchilas, hamsters, peixes, e pássaros também são utilizados em TAA (Kawakami \& Nakano, 2002). Quando a TAA utiliza somente cães, ela é chamada também de cinoterapia (Fiório, Anjos, Menegazzo \& Souza, 2013). Outra modalidade da TAA muito empregada atualmente também é a equoterapia, na qual são utilizados cavalos como recurso terapêutico para o desenvolvimento de habilidades de ordem psíquica e física (Copetti et al., 2007). Em Joinville, há um projeto no Hospital Infantil Dr. Jesser Amarante Faria que utiliza um cão fêmea da raça Golden Retriever para realização de terapia em crianças e adolescentes internados. Ela possui as vacinas em dia e antes de ir ao hospital, passa por uma higienização para evitar contaminação (Hospital Infantil Dr. Jeser Amarante Faria, 2014).

\section{Animal como Ferramenta Terapêutica para o Psi- cólogo}

Segundo Garcia (2009), dentre os profissionais de saúde que utilizam animais para fins de tratamento, o psicólogo é o que menos utiliza esse recurso. Os profissionais que mais aproveitam são médicos, fisioterapeutas, veterinários, fonoaudiólogos e terapeutas ocupacionais e também eles são maioria nas autorias da literatura disponível sobre esse tema. Porém, esse mesmo autor ainda coloca que o trabalho com cães para intervir no comportamento das pessoas mexe com fenômenos psicológicos, sendo então uma função do profissional de psicologia.

O psicólogo, ao utilizar o animal como recurso terapêutico, possui como um dos principais benefícios o estabelecimento do vínculo com o paciente, principalmente para aqueles que por algum motivo possuem dificuldades de comunicação e expressão, como crianças autistas, esquizofrênicos, pessoas com fobias e idosos. Por meio da espontaneidade do animal a pessoa pode ser estimulada e motivada a fazer algo sem se sentir forçada, possibilitando que o psicólogo inicie seu trabalho (Volpi \& Zadrozny, 2012).

\section{Aspectos negativos da relação com animais}

Entretanto, apesar de todos os benefícios que o animal pode proporcionar ao ser humano, é preciso também considerar os aspectos negativos desta relação. A convivência com animais aumenta a transmissão de zoonoses e os tutores podem ter alergias ao pêlo do animal. Além disso, a perda de um animal, seja por doença, desaparecimento ou roubo, pode acarretar muito sofrimento e angústia ao tutor, inclusive depressão (Miranda, 2011). 
Nessa convivência com os animais é preciso também levar em consideração os custos para cuidar deles, os riscos de receber mordidas e o desenvolvimento de fobias por animais (Costa, Jorge, Saraiva \& Coutinho, 2009).

\section{Metodologia}

O método de pesquisa utilizado foi a pesquisa qualitativa de abordagem fenomenológica, tratando a influência da convivência dos animais de estimação na perspectiva dos tutores. Foram realizadas entrevistas semiestruturadas que buscaram compreender a relação dos tutores com seus animais de estimação na percepção deles.

Após aprovação do Comitê de Ética (parecer $\mathrm{n}^{\circ}$ 715.639), a pesquisa foi realizada nas salas de estudos da biblioteca da UNIVILLE, individualmente, com seis estudantes universtiários que aderiram de forma aleatória. A pesquisadora esteve em uma sala de aula do período noturno e através do consentimento do professor, explanou para a turma de alunos presentes sobre a pesquisa e os convidou a responderem espontaneamente a entrevista. Houve rápida adesão de seis voluntários, suprindo a quantidade de participantes proposto no projeto de pesquisa.

Um termo de consentimento livre e esclarecido (TCLE) foi entregue para cada entrevistado, explicando o objetivo da pesquisa, esclarecendo que o nome do participante não é divulgado, mantendo assim a privacidade e integridade deles. As entrevistas foram gravadas com um gravador de áudio (mediante uma autorização de gravação de voz assinada pelos participantes) e posteriormente foram transcritas na íntegra pela pesquisadora, para dar fidedignidade aos relatos. O material vai ficar sob posse da pesquisadora responsável por um período de cinco anos e depois o mesmo será destruído. Utilizaram-se codinomes para garantir a privacidade dos participantes da pesquisa.

Para a iniciar a análise de dados, seguiu-se as etapas propostas por Amedeo Giorgi (1985). Na primeira etapa, foi realizada uma leitura das transcrições, com o objetivo de obter o sentido geral do que foi dito. Na segunda etapa, o conteúdo foi dividido em unidades de sentido, e na próxima etapa essas unidades foram transformadas em linguagem psicológica. Na quarta etapa, foi realizada uma síntese das unidades de significado, dividindo-as em categorias, trazendo os relatos de cada participante. No prosseguimento para análise de dados, foram realizadas etapas sugeridas por Coppe (2001): elaboração de uma tabela preenchida com o perfil de cada entrevistado, descrição e compreensão psicológica de cada unidade de sentido e categorização delas, formulação de uma discussão dessas unidades e suas significações.

\section{Análise dos resultados}

Abaixo segue o quadro com o perfil dos participantes da pesquisa:

Quadro 1: Idade, ocupação, estado civil e quais animais possuem os entrevistados.

\begin{tabular}{|c|c|c|c|c|c|}
\hline Nome & Idade & $\begin{array}{c}\text { Ocupação } \\
\text { Profissional }\end{array}$ & $\begin{array}{c}\text { Estado } \\
\text { civil }\end{array}$ & $\begin{array}{l}\text { Quantos } \\
\text { animais } \\
\text { possuem }\end{array}$ & $\begin{array}{c}\text { Quais } \\
\text { animais } \\
\text { possuem }\end{array}$ \\
\hline Maria & 21 & $\begin{array}{c}\text { Auxiliar de } \\
\text { contabilidade }\end{array}$ & Solteira & 1 & Cão \\
\hline Cláudia & 20 & $\begin{array}{l}\text { Vendedora de } \\
\text { acessórios }\end{array}$ & Solteira & 4 & $\begin{array}{c}\text { Cão e } \\
\text { Calopsita }\end{array}$ \\
\hline João & 22 & $\begin{array}{c}\text { Analista } \\
\text { comercial júnior }\end{array}$ & Solteiro & 4 & $\begin{array}{c}\text { Cão e } \\
\text { gato }\end{array}$ \\
\hline Pedro & 20 & Operador de caixa & Solteiro & 3 & $\begin{array}{c}\text { Cão e } \\
\text { gato }\end{array}$ \\
\hline Joana & 19 & $\begin{array}{c}\text { Auxiliar } \\
\text { administrativo }\end{array}$ & Solteira & 3 & Cão \\
\hline Rita & 30 & $\begin{array}{c}\text { Analista de } \\
\text { compras }\end{array}$ & Casada & 3 & Cão \\
\hline
\end{tabular}

Fonte: Primária, 2014.

Entre os entrevistados, predominam participantes do sexo feminino e solteiros. A média de idade é de 22 anos e cinco dos seis entrevistados possuem mais que dois animais de estimação. Todos os participantes possuem também no mínimo um cão.

As categorias de análise foram divididas em: tempo de convivência com animais, momentos de dedicação ao animal de estimação, sentimentos na interação com o animal, benefícios de ter um animal de estimação, aspectos negativos de ter um animal de estimação, a vida sem um animal de estimação, animal como membro da família.

\section{Tempo de convivência com animais}

A convivência com os animais vem de uma idade mais tenra:

"acho que quando eu era muito nova né, desde sempre minha mãe sempre teve cachorro.” (Maria)

“desde pequenininha, já tive vários.” (Cláudia)

"na minha casa sempre teve animais, desde pequeno meus pais sempre tiveram [...]” (João)

"desde sempre na verdade, minha mãe sempre gostou de gato, cão, sempre tive relação assim mais forte com gato, que eu gosto bastante de gatos, mas desde criança assim, acho que lá pelos cinco, sete anos.” (Pedro) "a gente sempre teve cachorro. A gente nunca ficou sem cachorro.” (Joana)

"acho que desde sempre, desde que eu me lembre minha mãe sempre teve né?” (Rita)

Segundo Lewin (1973), para compreender todo o comportamento de um indivíduo é necessário considerar que 
esse sujeito está inserido em um campo com o qual se relaciona, ou seja, o comportamento não depende somente de uma realidade interna, mas também de uma realidade externa, e essas realidades se influenciam. O sujeito não está apenas dentro de um campo, ele também é um campo, que está dentro de outro.

Dessa forma, ao interagir com diferentes meios, o homem possui também diferentes necessidades, acarretando comportamentos variados (Perls et al., 1997). Considerando a literatura encontrada e a resposta dos entrevistados, os animais de estimação estiveram inseridos no campo no qual esses indivíduos conviveram desde a infância, influenciando nas suas necessidades e comportamentos, portanto no decorrer da vida continuar criando animais de estimação é algo familiar para eles.

\section{Momentos de dedicação ao animal de estimação}

Cinco participantes contaram um pouco de sua rotina e quais os períodos do dia que ficam com eles:

"quando eu chego em casa, quando eu acordo, antes de dormir, depois do almoço, final de semana quando to em casa, que durante a semana que não vejo muito, só quando eu chego da faculdade.” (Maria)

"na verdade eu passo muito tempo fora de casa, eu trabalho o dia inteiro, venho para a faculdade [...] aí quando eu tenho tempo assim, sempre quando eu chego em casa, elas estão ali me esperando, aí vou fazer carinho.” (Cláudia)

"maior parte do tempo que eu tenho e passo com eles é de manhã [...] na hora depois que eu chego na faculdade onze horas sempre dou uma olhada lá atrás para ver como eles estão.” (João)

"todo dia que eu chego da faculdade eu que alimento, eu que dou água, brinco, de manhã também [...] mas final de semana se eu vou pra praia ele vai junto, porque assim ele é da minha responsabilidade, os outros acabam ficando em casa porque são mais velhos então ele a gente leva pra cima e pra baixo, se eu vou viajar ele vai junto, ta sempre junto.” (Joana)

"acho que sempre assim, é porque uma delas fica dentro de casa né, então ela ta sempre ali, dorme na cama, dorme na cama do meu filho, tá sempre com a gente, brincando com ela, de manhã quando a gente acorda e abre a porta já para as duas entrarem, elas tem acesso à casa também né, dou bom dia, converso com elas, o momento todo assim, dai a gente sai e dou tchau pra elas, eu meu marido e meu filho, e quando a gente volta elas também estão lá, então o tempo todo assim, sempre procuro estar perto.” (Rita)

Um participante relatou que procura seu animal de estimação quando está se sentindo triste:
"[...] geralmente quando são momentos que eu tô mais triste assim, mais sozinho, eu gosto de ficar sozinho com eles né, e no dia a dia também né, eu to sentado e eles ficam dentro de casa." (Pedro)

Dentre os entrevistados, quatro deles relataram que encontram seus animais de estimação quando chegam da faculdade, quatro falaram que no período da manhã ficam com seus animais e dois citaram o final de semana como um dos momentos com seus animais. Apenas um participante associou seus sentimentos com o momento de estar com o seu animal, relatando que o procura quando está triste.

Através da evolução, o homem passou a viver em uma sociedade pouco comunitária e mais individualista, afastando o indivíduo do seu meio natural de interação com outras espécies. Nesse sentido, a relação com animais de estimação é uma forma de busca desse contato com o meio natural (Lima \& Souza, 2004). O que esse autor traz vai ao encontro com o fato de que todos os entrevistados possuem em sua rotina momentos de dedicação ao animal de estimação, portanto eles permitem e buscam os seus animais de estimação para que entrem nos seus campos de contato.

\section{Sentimentos na interação com o animal}

Sobre os sentimentos que surgem da relação, quatro participantes citaram o sentimento de amor e três o sentimento de carinho:

"sentimento é de retribuição assim, você dá carinho e recebe carinho, parece que você dá amor pro bichinho e ele também te ama né?” (Maria)

Vale ressaltar que o objetivo neste estudo é se debruçar sob a percepção que as pessoas possuem sobre seu relacionamento com o animal de estimação, porém torna-se relevante inferir sobre o aspecto do animal nesta relação, uma vez que colocados sobre a dependência com o homem, este precisa de dedicação, reconhecimento, boas condições de local, higiene e uma alimentação adequada (Resende et al., 2006 conforme citado por Almeida, Almeida e Braga, 2009).

"[...] nossa é um amor muito grande, é uma coisa muito gostosa sabe, tipo tu fica fazendo careta, brincando com ela e nem se liga se tem alguém te vendo, se tu ta na rua, independente, acho que te leva para um lugar assim que tu sai e fica ali com ela sabe?” (Cláudia) "sentimento de carinho, de amor assim, que, como eu posso dizer, que se acontecesse uma coisa com ele eu ia ficar bem triste assim sabe?” (Pedro)

"eles passam uma coisa boa assim, energia boa, um carinho, um amor” (Joana) 
Os animais podem ser considerados como uma fonte de amor (Faraco, 2003) e nessa relação homem-animal ocorre também uma busca por carinho (Leal, 2007 conforme citado por Barbosa, 2013). Segundo Polster e Polster (2001), o contato faz parte da natureza e sem ele não há vida. Nesse sentido, o contato com o outro então é algo nutritivo para o homem. Segundo Perls et al. (1997) no contato o homem se relaciona consigo, com o outro e com o mundo, formando um ser de relação. O contato pode também ser uma forma de o ser humano se ajustar de forma criativa no meio. Dessa forma, ao ter contato com seus animais de estimação, os entrevistados relatam que nessa relação surgem sentimentos que eles nomeiam como amor e carinho. Seguindo uma esfera fenomenológica, não foi aprofundado o significado que os entrevistados dão aos sentimentos de amor e carinho.

Também apareceram sentimentos de alegria, compaixão, sentimento de não estar só, de alívio por ter a companhia do animal, sensação de relaxamento.

"alegria, amor, compaixão, carinho, de alívio por terem elas comigo, porque como eu disse ela são muito velhinhas." (Cláudia)

"é um momento que eu relaxo, esqueço os problemas que eu tenho durante a semana, vida de estudante, então chego muito sobrecarregado em casa, então tem uma coisa para aliviar, quando não é o videogame ou a noiva." (João)

"o que eu sinto assim é alegria né, que eles são uma companhia, e sinto que eu não estou só. Mesmo quando não há nenhum ser humano comigo assim que eu fico sozinha, que não tem ninguém em casa né, elas me fazem companhia, eu nunca fico só.” (Rita)

Esses relatos vão ao encontro com o citado por Kitagawa e Coutinho (2004), que coloca que os animais também proporcionam sensação de relaxamento, e com Costa (2006), que traz que a convivência com animais proporciona estados de felicidade e diminuem o sentimento de solidão. Não foram investigados como os sentimentos relatados são vivenciados na visão de cada entrevistado.

\section{Benefícios de ter um animal de estimação}

Em relação aos benefícios de ter um animal de estimação, o elemento mais citado (por quatro participantes) foi o sentimento de alegria, seguido de companheirismo (relatado por três participantes):

"uhum... uma companhia, não só para as pessoas que são sozinhas, que moram sozinhas, mas traz uma alegria, traz carinho." (Maria)

"ele vem trazer alegria pra você, então acho que o primeiro estágio é alegria, né e o outro é o companheirismo, né o tempo passa e ele sempre vai estar ali contigo também, cara até o resto da vida dele né, e sempre tá presente também, é uma coisa assim que tu desenvolve uma relação então são esses três pontos que eu finalizo também com a amizade." (João)

"traz mais alegria, tipo, felicidade assim." (Pedro) "além de não sentir solidão, é sempre uma companhia, eu acho que eles estão sempre te dando alegria." (Rita)

A companhia é um dos benefícios da convivência com animais de estimação (Heiden \& Santos, 2009), e esta literatura vem ao encontro com o relato dos participantes acima. Cada entrevistado possui a sua maneira de vivenciar a companhia do animal, porém esse aspecto não foi aprofundado. Outra participante respondeu que a convivência com o animal traz o benefício da cura de algumas doenças:

"[...] eu acredito sim que eles tem um poder te ajudar na cura de algumas doenças, eu acredito que se eles entram em contato com crianças com problemas de saúde ajudam muito, eu acredito nisso, né.” (Joana)

Uma das entrevistadas respondeu também que a pessoa que convive com um animal de estimação tem o benefício de ter compaixão, ser mais aliviada, menos fria:

"eu acho que a pessoa que tem um animal de estimação ela é, querendo ou não ela é mais aliviada assim, ela tem mais compaixão sabe, no olhar, ela não é tão fria." (Cláudia)

O que foi relatado pela participante acima vai ao encontro com Heiden \& Santos (2009), que traz que os animais podem causar mudanças positivas no comportamento das pessoas. A forma como a entrevistada experimenta a compaixão e o alívio não foi investigado.

\section{Aspectos negativos de ter um animal de estimação}

Dois participantes relataram que não há nenhum malefício em ter um animal de estimação e complementam falando sobre as necessidades fisiológicas deles:

"hmm não. Pra mim não, do meu cachorro eu não vejo nenhum né, ah fez xixi dentro de casa né, mas é uma coisa muito esporádica." (Maria)

"ai eu não vejo, eu gosto muito assim, é não tem assim... limpar o cocô? Hahaha mais assim, acho que não tem malefício.” (Joana)

Dois indivíduos comentaram sobre algumas dificuldades na convivência com o animal:

"chinelo, tu tem que correr atrás para pegar, aí tem a questão de subir no sofá, tu tem que educar.” (João)

"vou falar em relação ao meu gato, que quando eu tô dormindo ele vem me incomodar assim, e isso eu não 
gosto, tipo ah tô dormindo, ele consegue abrir a janela do meu quarto, e quando tô dormindo pegando no sono ele vem assim e abre a janela e dai a gente leva susto assim, essa parte assim que eu acho incômodo." (Pedro)

Uma entrevistada diz que os aspectos negativos da convivência com animais são as doenças que eles podem transmitir ao ser humano:

“sim, na verdade até se tu não cuida assim tem um monte de doença que pode trazer sabe, a minha mãe não tem gato porque minha mãe tem uma doença causada pelo pêlo do gato.” (Cláudia)

Esse relato vai ao encontro com o que é descrito por Miranda (2011), que coloca que na convivência com os animais é preciso tomar cuidado com a transmissão de zoonoses, que podem ser transmitidas através do contato com as fezes e saliva do animal (Zetun, 2009). O fato de os animais terem vida mais curta que os humanos, foi trazido como malefício para um sujeito:

"a única coisa ruim que eu posso pensar deles é que eles se vão antes de nós assim, eles têm uma vida muito curta." (Rita)

Ao lidar com a morte de um animal, o indivíduo pode revelar sentimentos dolorosos e intensos (Gardemann et al., 2009 conforme citado por Barbosa, 2013), caracterizando, dessa forma, como um aspecto negativo de ter um animal de estimação.

\section{A vida sem um animal de estimação}

Em relação a uma vida sem um animal de estimação, um participante respondeu como ficaria a situação em casa:

"acho que seria mais sozinha a casa, [...] acho que a casa seria mais parada, mais silenciosa, enfim.”(Maria)

Outro entrevistado relatou o sentimento de solidão:

"horrível, horrível, acho que eu me sentiria muito sozinha, éé sei lá é estranho pensar nisso sabe? Não ter um cachorrinho sabe, pra fazer carinho, ou um gatinho, ou alguma coisa do tipo, não sei, é estranho, eu acho que eu me sentiria muito sozinha, uma pessoa assim que qualquer coisa ia querer levar pra casa sabe?” (Cláudia)

A relação homem-animal pode trazer alívio de sentimentos de solidão e angústia (Leal, 2007 conforme citado por Barbosa, 2013), portanto sem esse animal de estimação, confirmado pelo discurso acima, surge a solidão, porém somente a entrevistada poderia descrever como é a solidão dela. O sentimento de perda e de vazio também aparece na resposta de um entrevistado:

"eu desenvolveria amizade com a televisão, porque seria depois a próxima companhia, um sentimento de vazio ficaria, hoje se tirassem meus cachorros lá de casa hoje eu sentiria um baque, é um sentimento de perda. (João)

O sentimento de perda de um animal de estimação pode acarretar sofrimento e mudanças na vida de uma pessoa (Barbosa, 2013). Conforme visto no discurso de João, uma de suas mudanças seria desenvolver a amizade com a televisão. Segundo Sant'Anna (2013) a televisão produz de forma imediata uma nova realidade, que muitas vezes é diferente da realidade que a pessoa que assiste vive. Sendo assim, a interação com a televisão pode ser uma possibilidade de lidar com algum sofrimento da perda do animal de estimação. Um dos sujeitos respondeu que não passaria mais seus momentos tristes com uma companhia:

"eu não ia ter momentos de, por exemplo, quando eu tô triste, meu gato sempre vem comigo, então sem ele eu ia ficar mais desanimado assim, em um momento triste assim né, que eles que me alegram né, querendo ficar sozinho mas a presença deles me alegra.”(Pedro)

Uma das pessoas entrevistadas trouxe o sentimento de tristeza:

“acho que eu seria mais triste talvez né?” (Rita)

Barbosa (2013) traz que a ausência de um animal de estimação pode causar tristeza, mas a forma como cada um vivencia esse sentimento é diferente. Outro participante colocou que não sabe se seria feliz do que jeito que é e acha que não teria vida sem um animal de estimação:

"eu não sei se eu seria feliz do jeito que eu sou [...] então acho que não tem vida sem um animal eu acho." (Joana)

\section{Animal como membro da família}

Surgiram de dois entrevistados discursos em que os animais de estimação são considerados como membro da família:

"não tem mais criança e a gente meio que considera nosso cachorro a criança da casa [...] ela entra dentro de casa, sobe no sofá, ela pode fazer tudo, eu digo que quando eu era criança eu não podia fazer o que ela faz, é quase uma filha, minha mãe às vezes até me chama pelo nome do cachorro.” (Maria) 
"muita coisa eu contei já pra um cachorro que eu não contei para mais ninguém, desabafar, mas é um sentimento assim é como um ser da família na verdade, é um irmão irracional.” (João)

Costa et al. (2009), Martins et al. (2013) e Barbosa (2013) consideram que os animais cada vez mais são considerados como membros da família. Kidd e Kidd (1997) relata ainda que os indivíduos que conviveram com animais desde a infância, quando adultos consideram os animais de estimação como parte da família, e acabam repassando esse comportamento para os filhos e incentivando outras pessoas a atuarem da mesma maneira.

Através da pesquisa fenomenológica, realizando entrevistas semiestruturadas buscou-se com esse trabalho compreender a influência da convivência com os animais de estimação na vida das pessoas a partir da percepção de seus tutores. Nas referências utilizadas para elaborar esse artigo no qual o tema era a relação homem-animal, a maioria foram da área de Psicologia. Surgiram também autores da área de veterinária, enfermagem e fisioterapia, campos em que segundo Garcia (2009) utilizam mais o animal como recurso para tratamentos se comparado ao profissional de Psicologia. Entretanto, considerando a quantidade de referencial bibliográfico encontrado para essa pesquisa na área de Psicologia, pode-se perceber que o tema relação homem-animal já vem sendo alvo de atenção desses profissionais.

No discurso dos participantes desta pesquisa foi possível perceber que todos convivem com animais desde a infância. Os sentimentos associados com a relação foram de amor e carinho. Os sentimentos de perda, tristeza e solidão foram associados a uma vida sem um animal de estimação. Os aspectos negativos da convivência com os animais foram trazidos em sua maioria sob a forma de dificuldades como limpar as fezes do animal, educar para que eles se comportem, não destruindo objetos pessoais e nem estando em lugares onde não podem estar. Surgiu de uma minoria dos participantes os malefícios de transmissão de zoonoses e do fato de os animais terem um tempo de vida menor do que o dos humanos. Os benefícios associados à convivência com o animal de estimação foram o companheirismo, a alegria, o desenvolvimento de maior compaixão e a ajuda que podem oferecer na cura de algumas doenças. Os animais também foram citados como membro da família. Sendo assim, o contato com o animal de estimação para essa população pesquisada obteve mais elementos positivos do que elementos negativos.

\section{Considerações finais}

Os animais fazem parte da vida cotidiana dos entrevistados. Segundo Goldstein (1939/2000) a maneira que os sujeitos utilizam para se relacionar com o mundo é uma forma de regular o próprio organismo, ou seja, é uma das características principais do funcionamento do ser vivo. Dessa forma, o convívio com animais, para essa amostra, pode ser uma alternativa que contribui na autorregulação.

As espécies de animais de estimação encontradas no grupo pesquisado são os cães e os gatos, que se encaixam na definição de Animais da Fauna Doméstica, conforme a Portaria/IBAMA nº93, de 07 de julho de 1998:

"todos aqueles animais que através de processos tradicionais e sistematizados de manejo e/ou melhoramento zootécnico tornaram-se domésticas, apresentando características biológicas e comportamentais em estreita dependência do homem podendo apresentar fenótipo variável, diferente da espécie silvestre que os originou”.

Evidencia-se que na população entrevistada uma característica relevante é que todos possuem animais de estimação desde a infância. Ter ou não vivência anterior com animais na infância não foi considerado como critério de inclusão/exclusão no momento da escolha dos participantes da pesquisa. Esse fenômeno pode ter influenciado nas respostas, que em sua maioria foram muito parecidas e voltadas para uma tendência de percepção valorativa dos aspectos bons da convivência com animais. Assim aponta-se para a importância de fomentar novas pesquisas nesta temática, com pessoas que tiveram animais de estimação somente na idade adulta ou que não possuem animais, para ter uma real percepção mais apurada do quanto a convivência com animais de estimação na infância pode influenciar na vida adulta das pessoas.

Outro aspecto observado foi a facilidade de adesão à pesquisa. Ao expor e explicar o tema, os participantes prontamente se disponibilizaram para participar, não havendo dificuldade na adesão. Outras pessoas também se mostraram interessadas em participar, porém o número total previsto para a pesquisa já havia sido completado. Assim, encontramos um tema que parece ser instigante para ser pesquisado. Isto pode estar relacionado com o fato de que os animais de estimação estão cada vez mais presentes na vida das pessoas, tornando essa relação significativa em diversos aspectos.

É interessante registrar aqui os aspectos não verbais demonstrados pelos participantes enquanto falavam durante a entrevista. Muitos alteravam as expressões faciais que refletiam as alterações emocionais. Alguns entrevistados, ao expor de seus sentimentos pelos seus animais, falavam sorrindo, os olhos ficavam marejados. Uma das participantes, ao falar sobre como seria sua vida sem seus animais, chorou. É possível perceber que o tema da pesquisa tocou os entrevistados, e traz a reflexão de que ainda há necessidade de falar sobre a relação do homem com os animais de estimação.

As limitações encontradas nesta pesquisa e que abrem possibilidades de novos estudos são sobre a precariedade 
nas referências no campo da psicologia voltado especificamente para esse tema, a influência que a vivência anterior com animais de estimação tem na percepção atual do grupo pesquisado e os aspectos que essa relação traz aos animais. Conclui-se que os resultados foram alcançados, o fenômeno pode ser observado através da verbalização nas entrevistas gravadas e quando analisados e categorizados houve predomínio de aspectos positivos na relação do tutor com seu animal de estimação.

\section{Referências}

Abinpet. Associação Brasileira da Indústria de Produtos para Animais de Estimação (2014). Disponível em http://abinpet. org.br/site/

Almeida, M.L., Almeida, L.P. \& Braga, P.F.S. (2009). Aspectos psicológicos na interação homem-animal de estimação. IX encontro interno \& XII Seminário de Iniciação Científica. Recuperado em Novembro de 2015, de https://ssl4799.websiteseguro.com/swge5/seg/cd2009/PDF/IC2009-0113.pdf.

Anderson, D. C. (2006). Measuring the bond: instruments used to assess the impact of animal-assisted therapy. Em Fine, A. H., Handbook on animal-assisted therapy: Theoretical Foundations and Guidelines for Practice (p. 391-411). San Diego: Elsevier.

Barbosa, C. V. (2013). Quando o melhor amigo é um cão: reflexões sobre o impacto da morte de animais de estimação (Trabalho de conclusão de curso de Psicologia). Faculdade do Vale do Ipojuca- FAVIP, Caruaru.

Barros, C. T. (2008). Possibilidades de utilização da terapia assistida por animais (TAA) na Terapia Ocupacional (Trabalho de Conclusão de Curso de Terapia Ocupacional). Fundação Educacional Lucas Machado, Belo Horizonte.

Berzins, M. A. V. S. (2000). Velhos, cães e gatos: interpretação de uma relação (Dissertação de Mestrado em Gerontologia). Pontificia Universidade Católica de São Paulo, São Paulo.

Bogado, C. H. D. \& Ceres, B. F. (2009). Repercussão da Terapia Mediada por Animais sobre o comportamento pró-social em criança institucionalizada: um estudo de caso (Trabalho de Conclusão do curso de Psicologia). Faculdades Integradas de Taquara, Taquara.

Brasil (1934). Decreto $n^{\circ} 24645$, de 10 de julho de 1934. Dispõe sobre medidas de proteção aos animais. Presidência da República.

Brasil (1998). Lei $n^{0}$ 9605, de 12 de fevereiro de 1998. Dispõe sobre as sanções penais e administrativas derivadas de condutas e atividades lesivas ao meio ambiente, e dá outras providências. Presidência da República.

Brasil (1998). Portaria nº 93, de 07 de julho de 1998. Importação e exportação fauna silvestre. Brasília: IBAMA.

Buber, M. (1974). Eu e Tu. São Paulo: Moraes.
Caetano, E. C. S. (2010). As contribuições da TAA- Terapia Assistida por Animais à Psicologia (Trabalho de Conclusão de Curso de Psicologia). Universidade do Extremo Sul Catarinense- UNESC, Criciúma.

Copetti, F., Mota, C. B., Graup, S., Menezes, K. M. \& Venturini, E. B. (2007). Comportamento angular do andar de crianças com Síndrome de Down após intervenção com equoterapia. Revista Brasileira de Fisioterapia, 11(6), 503-507.

Coppe, A. F. (2001) A vivência em grupos de encontro: um estudo fenomenológico de depoimentos (Dissertação). Universidade Federal do Rio de Janeiro, Rio de Janeiro.

Costa, E. C. (2006). Animais de estimação: uma abordagem psico-sociológica da concepção dos idosos (Dissertação de Mestrado em Saúde Pública). Universidade Estadual do Ceará, Fortaleza.

Costa, E. C. Jorge, M. S. B., Saraiva, E. R. A. \& Coutinho, M. P. L. (2009). Aspectos psicossociais da convivência de idosas com animais de estimação: uma interação social alternativa. Psicologia: teoria e prática, 11(3), 2-15.

Delarissa, F. A. (2003) Animais de estimação de objetos transacionais: uma aproximação psicanalítica sobre a interação homem-animal (Dissertação de Mestrado em Psicologia). Universidade Estadual Paulista (UNESP), Assis

Dotti, J. (2005). Terapia \& Animais. São Paulo: Livrus.

Faraco, C. B. (2003). Animais em sala de aula: um estudo das repercussões psicossociais da intervenção mediada por animais (Dissertação de mestrado em Psicologia)-Pontifícia Universidade Católica do Rio Grande do Sul, Porto Alegre.

Fiório, F. B., Anjos, M. C. M., Menegazzo, A. D. \& Souza, V. S. W. (2013). Influência da Cinoterapia e perfil do animal durante exercícios fisioterapêuticos: um estudo de caso. FisiSenectus, 1. Recuperado em Fevereiro de 2014, de http://bell. unochapeco.edu.br/revistas/index.php/fisisenectus/article/ viewFile/1768/982.

Franco, V. L. (2001). A relação homem e animal. Revista Digital Isto É. Recuperado em abril de 2016, de http://www.terra. com.br/planetanaweb/341/.

Fuchs, H. (1987). O animal em casa (Dissertação de Doutorado em Ciências). Instituto de Psicologia, USP, São Paulo.

Garcia, M. P. (2009). Classes de comportamentos constituintes de intervenções de psicólogos no subcampo de atuação profissional de psicoterapia com apoio de cães (Dissertação de mestrado em Psicologia). Universidade Federal de Santa Catarina, Florianópolis.

Giorgi, A. (1985). Sketch of a psychological phenomenological method. Em Giorgi A. (Org.), Phenomenology and psychological research (p. 8-22). Pittsburg: Duquesne University Press.

Goldstein, K. (2000) The organism: a holistic approach to biology derived from pathological data in man. Nova York: Zone Books (Originalmente publicado em 1939).

Hart, B. L. (1985). The behaviour of Domestic Animals. Nova Iorque: W.H Freeman and Company. 
Heiden, J. \& Santos, W. (2009). Benefícios psicológicos da convivência com animais de estimação para idosos. Àgora, revista de iniciação científica, 16(2), 487-496.

Hospital Infantil Dr. Jeser Amarante Faria (2014). Disponível em http://www.hjaf.org.br/index.php/comunicacao/ noticias/93-nt3.

Jornal do Município de Joinville (2013). Disponível em https:// www.joinville.sc.gov.br/public/portaladm/pdf/jornal/64c0e 28aae10df475db1fd03fa176852.pdf.

Kawakami, C. H. \& Nakano, C. K. (2002). Relato de experiência: terapia assistida por animais (TAA) - mais um recurso de comunicação entre paciente e enfermeiro. Simp.Bras.Comun. Enferm. Recuperado em Fevereiro de 2014, de http://www. proceedings.scielo.br/scielo.php?pid =MSC000000005200 2000100009\&script $=$ sci_arttext\&tlng $=$ pt.

Kidd, A. H., \& Kidd, R. M. (1997). Change in the behavior of pet owners across generations. Psychological Reports, v. 80.

Kitagawa, B. Y. \& Coutinho, S. D. A. (2004). Benefícios advindos da interação homem-cão. Revista Ins.Ciên.Saúde, 22(02). Recuperado em Setembro de 2014, de http://bases.bireme.br/ cgi-bin/wxislind.exe/iah/online/?IsisScript=iah/iah.xis\&src

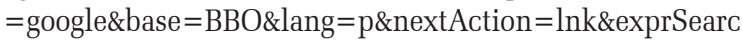
$\mathrm{h}=23608 \&$ indexSearch $=$ ID.

Levine, M. (1999). Investigating the origins of horse domestication. Equine Veterinary Journal Supplement, 31(528), 6-14.

Lewin, K. (1973). Princípios de Psicologia Topológica. São Paulo: Cultrix.

Lima, M. \& Souza, L. (2004). A influência positiva dos animais de ajuda social. Interacções, 6, 156-174.

Martins, M. F., Pieruzzi, P. A. P., Santos, J. P. F., Brunetto, M. A., Fruchi, V. M., Ciari, M. B., Luppi, M. J. R. \& Zoppa, L. M. (2013). Grau de apego dos proprietários com os animais de companhia segundo a Escala Lexington Attachment to Pets. Braz.J.Vet.Res.Anim.Sci, 50(5). Recuperado em Setembro de 2014, de http://www.revistas.usp.br/bjvras/article/ viewFile/79925/83866

Miranda, M. I. L. A. R. M. (2011). A importância do vínculo para os donos de cães e gatos nas famílias portuguesas (Dissertação de mestrado em Medicina Veterinária).Universidade do Porto, Porto.

Nebbe, L. (2000). Nature Therapy. Em Fine, A. H., Handbook on Animal Assisted Therapy: Theoretical Foundations and Guidelines for Practice (p. 385-414). San Diego: Academic Press.

Perls, F., Hefferline, R. \& Goodman, P. (1997). Gestalt-Terapia. São Paulo: Summus.

Polster, E. \& Polster, M. (2001). Gestalt-terapia Integrada. São Paulo: Summus.

Prefeitura de Araquari (2014). Disponível em http://www.araquari.sc.gov.br/noticia/623/araquari-cria-lei-de-protecaoaos-animais.

Sant'Anna, R. (2013). Pós-modernidade, imagem e reencantamento: o papel da televisão. Recuperado em Novembro de
2015, de http://paginas.unisul.br/agcom/revistacientifica/ artigos/artigo_ronaldosantana.pdf.

Tatibana, L. S. \& Costa-Val, A. P. (2009). Relação homem-animal de companhia e o papel do médico veterinário. Revista Veterinária e Zootecnia em Minas, n. 103. Recuperado em Fevereiro de 2014, de http://www.crmvmg.org.br/RevistaVZ/ Revista03.pdf\#page $=11$.

Vivaldini, V. H. (2011). Terapia Assistida por Animais: Uma aborgadem lúdica em Reabilitação clínica de pessoas com deficiência intelectual (Dissertação de mestrado em Psicologia da Saúde). Universidade Metodista de São Paulo, São Bernardo do Campo.

Volpi, D. \& Zadrozny, V. G. P. (2012). Benefícios da TAA: Uma contribuição da Psicologia (Trabalho de conclusão de curso de Psicologia). Universidade Regional de Blumenau, Blumenau.

Walsh, F. (2009). Human-Animal bonds I: The relational significance of companion animals. Family Process, 48(4).

Raísa Duquia Giumelli - Graduada em Psicologia na Universidade da Região de Joinville (Univille), cursando especialização em Psicologia clínica na abordagem gestáltica no Centro de Estudos de Gestalt-Terapia de Santa Catarina (Ceg), Psicóloga Clínica e voluntária no Centro de Estudos e Orientação da Família (Cenef). Endereço Institucional: Rua Germano Wetzel, n ${ }^{0}$ 128. Bairro: Bom Retiro. Joinville-SC. CEP: 89223010. E-mail: raisapsicologia@gmail.com

Marciane Cleuri Pereira Santos - Psicóloga clínica, Especialista em Gestalt Terapia, Mestre em Saúde e Meio Ambiente pela Universidade da Região de Joinville (Univille), Professora e Supervisora Clínica de Estágio de Psicologia Clínica na Universidade da Região de Joinville (Univille).

Recebido em 24.06.2015 Primeira Decisão Editorial em 20.10.2015 Segunda Decisão Editorial em 20.02.2016 Aceito em 07.04.2016 